\title{
On International Fisheries Agreements, Entry Deterrence and Ecological Uncertainty
}

\author{
by \\ Hans Ellefsen, \\ Lone Grønbæk Kronbak \\ and \\ Lars Ravn-Jonsen
}

Discussion Papers on Business and Economics

No. $18 / 2014$

FURTHER INFORMATION

Department of Business and Economics Faculty of Business and Social Sciences University of Southern Denmark Campusvej 55

DK-5230 Odense M

Denmark

Tel.: +45 65503271

Fax: +45 65503237

E-mail:1ho@sam.sdu.dk http://www.sdu.dk/ivoe 


\title{
On International Fisheries Agreements, Entry Deterrence and Ecological
}

\section{Uncertainty}

\author{
Hans Ellefsen ${ }^{\mathrm{a}}$, Lone Grønbæk Kronbak ${ }^{\mathrm{b}, *}$, Lars Ravn-Jonsen $^{\mathrm{c}}$ \\ ${ }^{\text {a }}$ University of Faroe Islands, J.C. Svabos gøta 14, FO-100 Tórshavn, Froe Islands. \\ ${ }^{\mathrm{b}}$ Department of Business and Economics, University of Southern Denmark, Campusvej 55, DK-5230 Odense M, \\ Denmark. \\ ${ }^{c}$ Department of environmental and Business Economics, University of Southern Denmark, Niels Bohrs Vej 9, DK-6700 \\ Esbjerg, Denmark.
}

\begin{abstract}
From a game theoretical perspective, a prerequisite for an international fishery agreement (IFA) to be stable is that parties expect their benefits from joining the agreement to exceed the benefits from free riding on the agreement, and parties only comply with the agreement as long as this is true. The agreement, therefore, implicitly builds on an expectation of the ecological integrity of the natural resource. Typically, the game theoretical models assume that all parties have the same (often perfect) information of the resource and that the exploitation is an equilibrium use of the stock. As stated by experts in natural science, the fish ecology still has many open questions, e.g. how to predict population dynamics, migration patterns, food availability, etc. In some cases, parties disagree about the state, abundance, and migration of a stock, which can significantly disturb the possibilities of reaching an agreement for exploitation of the stock. This paper develops a model and applies it to the North-East Atlantic mackerel fishery, in order to analyze IFA under different ecological scenarios, and also combines the model with the economic theory of entry deterrence. The model is empirically used to determine whether the original parties to the agreement have an advantage in that the results from fishing the stock down to a smaller size prevents another party from entering into the fishery. The paper presents a novel method for illustrating the obstacles that have made an agreement for the North-East Atlantic mackerel so difficult to achieve.
\end{abstract}

Keywords: Cooperative game, Nash game, Entry deterrence, Stability of sharing rule, Bioeconomic modeling, ecological uncertainty

JEL Classification: D74, C71, C62, Q22

\footnotetext{
* Corresponding author. 


\section{Introduction}

Debates about the use of common resources are everlasting. In the literature on shared fishery resources the debate dates back to Warming (Warming, 1911), who, in his original contribution, debated the problem of what was later called open access. More widely known is the manuscript by Gordon (1954) dealing with same type of problem. If the rights to use the commons are too widely distributed, it often results in the tragedy of the commons; for example, if herdsmen share a common grazing field for their cattle, the common use of the grazing field results in over-use due to the conflict between private and common incentives. In fishery the problem is all too familiar. Here there are two levels of conflicts, i) the nations trying to secure the fishery resources for their fishermen and ii) the fishermen competing for the resources the nation has secured or fishermen competing for resources not allocated to any nation. In this paper we address the nation level i only.

Debates over the rights to shared fishery resources are still ongoing. A recent example from 2014 involves a general fishing moratorium on fish in the central Arctic Ocean, which due to the melting ice will become accessible. The agreement was made among the five nations surrounding this ocean. This endeavor of nations to secure resources at sea began after the Second World War, where several states attempted - unilaterally - to secure fishery resources by extending their territorial limits at sea outside the 3 nautical mile zone (later 12 nautical mile zone).

Many attempts to reduce the conflicts over shared resources have been made. The most significant conference, convened by the United Nations (UN), to regulate the use of the oceans lasted from 1973 to 1982 and resulted in an agreement called the United Nations Convention on the Law of the Sea (UNCLOS), (United Nations, 1982). The UN convention from 1982 establishes the 200 nautical mile exclusive economic zone (EEZ), which is considered as a major step towards establishing property rights for shared resources. Because $90 \%$ of the fisheries were in the hands of the coastal states at that time, the dominant belief was that the EEZs would not lead to conflicts between these coastal states and would thereby prevent the depletion of fish stocks. However, this has proven to be far from the truth (Munro, 2008). The disputes about management of straddling stocks, in many cases resulting in overexploitation, remained unsolved. First, stocks migrating through more than one EEZ and the high seas became a subject of conflict between the fisheries nations. Second, the remaining high seas became a place to fish unregulated for those fishery nations with insufficient fish resources in their EEZs. It became clear that the management of the straddling fish stocks was not acceptable. Therefore, in 1995, the UN negotiated another agreement to supplement and strengthen the UNCLOS, called the 'UN Fish Stocks Agreement' (UNFSA) (United Nations, 1995; Bjørndal and Munro, 2003). The UNFSA facilitates agreements among all parties with a real interest in the fisheries on the management of straddling stocks through regional 
fisheries management organizations (RFMOs) (United Nations, 1995; Bjørndal and Munro, 2003). Today, many RFMOs exist, of which several predate the UNSFA; e.g., the North-East Atlantic Fisheries Commission (NEAFC), the Northwest Atlantic Fisheries Organization (NAFO), and the International Commission for the Conservation of Atlantic Tunas (ICCAT). The membership of the RFMOs typically consists of the coastal states in the respective area and certain distant water fishing nations that do not have coastal state status but may have a history of fishing certain species.

Despite the UNFSA there are, when it comes to the cooperative management of straddling fish stocks under RFMOs, still issues left unsolved (Munro, 2007). One such issue, often referred to as the new member problem (Kaitala and Munro 1997; Pintassilgo and Duarte, 2000), is the problem of new parties having an interest in exploiting the stock. Some real world examples of the new member problem are the case of the North-East Atlantic mackerel, which Iceland has had an economic interest in exploiting in recent years, and the case of the bluefin tuna in the Mediterranean Sea, where new distant-waters fishing nations turn up at regular intervals. The model presented here touches upon the new member problem, but has only a single player as a new entrant. The new entrant turns up as a consequence of the change in the ecological state of the stock, in contrast to situations where the stock is constantly available in the high sea, and where there is a fringe of distant-water fishing nations.

International agreements are rooted in traditional cooperative game theory and are based on the first-best solution with an overarching aim of full rent maximization. This is an intriguing thought, but methodologically and theoretically it requires a transferable utility game (TU game) where sidepayments among the parties are allowed. The TU coalition game approach, however, can still be an efficient tool for finding a fair way to share the resource such that all players are satisfied and do not have incentives to free ride on the agreement (Kronbak and Lindroos, 2007). This may be a tool for the sharing of total allowable catches (Lindroos et al. 2007; Kronbak and Lindroos, 2013).

From a game theoretical perspective, one prerequisite for an international fisheries agreement to be stable is; the parties expect their benefits from joining the agreement to exceed the benefits from free riding on the agreement, and the parties only comply with the agreement as long as this is true. The agreement, therefore, builds on each party's expected payoff from the exploitation of the resource, and thus implicitly builds on similar expectations of the ecological condition of the natural resource. Typically, the game theoretical models assume that all parties have the same, often perfect, information of the resource and that the exploitation is an equilibrium use of the stock. As described by experts of natural science, like the $\mathrm{ICES}^{1}$, the fish ecology still has many open questions, e.g.

\footnotetext{
${ }^{1}$ International Council for the Exploration of the Sea (www.ICES.dk). 
explain and predict the population dynamics, migration patterns, food availability, etc. In some cases, parties disagree about the state, the abundance, and the migration of a stock. The ecological settings define the framework conditions for the negotiations, and hence disagreement about these conditions increases the level of complications for reaching an agreement. This paper contributes by allowing for cases where parties have different views on the ecology of a fish stock, which changes the setting of the game. The model demonstrates, by its empirical application to the Northeast Atlantic mackerel (scomber scombrus), that this change in the fundamental perception of the ecological conditions of the stock is likely to imply that an international agreement is difficult to implement and sustain, since alternative strategies may be more attractive.

\section{The Case of the Northeast Atlantic Mackerel}

The Northeast Atlantic (NEA) mackerel is an economically important species in the pelagic fishery of many coastal states in northern Europe. It has been exploited for decades, and the EU and Norway have shared this stock since the 1970s, while in particular Russian vessels have exploited the stock in Faroese waters since the 1980s. In 2000 the coastal states of the EU, Norway and the Faroe Islands implemented an agreement on the sharing of harvest in the NEA mackerel fishery. The agreement was made in the realm of the NEAFC, and as a member state of NEAFC Russia receives a smaller share $(5 \%)$ in the international area. The Faroese were allocated $5 \%$ of the total quota, while the EU and Norway shared the remainder of the quota, with an approximate $70 \%$ share for EU and 30\% share for Norway. This agreement was stable and re-negotiated with the same percentages for a couple of years. However, in 2007 the migration pattern of the mackerel stock changed; unprecedented the stock entered the Icelandic EEZ. The Icelanders began fishing the mackerel in significant quantities starting in 2008 (Ellefsen, 2013). The Icelanders were invited to the negotiations concerning the 2010 fishery quotas. Still the parties did not reach an agreement, and the Faroe Islands, as they were no longer satisfied with their share of the total stock, left the existing 2000 agreement, while the EU and Norway entered a bilateral agreement. After four years of meetings ${ }^{2}$ a three-party agreement on the mackerel between the EU, Norway, and the Faroe Islands was signed in March 2014. Due to disagreements on how to share the harvest of the mackerel stock, Iceland was not a coalition partner in the agreement. Yet another issue has come up since 2013: Greenland has entered the fishery and is harvesting fairly large amounts of the mackerel (expected 100,000 tons in 2014). The existing harvest of the stock by the original coastal states in combination with the fishing activity of Iceland, and lately Greenland, implies that every year since

\footnotetext{
${ }^{2} 22$ meetings held in the period 2010-2013 (Source: personal communication: Jógvan Jespersen, director for Faroese Purse Seiners organization). 
2008 the mackerel harvest have been well above the level recommended by the ICES biologists (ICES, 2012), as illustrated in Figure 1.

However, due to uncertainties about the ecological conditions, the biologists have recently abolished their former biological model (ICES, 2013), resulting in the total allowable catches (TAC) for 2014 having been raised substantially. ${ }^{3}$ Implicitly this raises the question whether the biological information for the preceding years has been accurate, with a sudden major increase in the biomass or the biomass have been underestimated in preceding years (ICES, 2014).

Figure 1: Actual and recommended mackerel fishery from 2000 to 2014

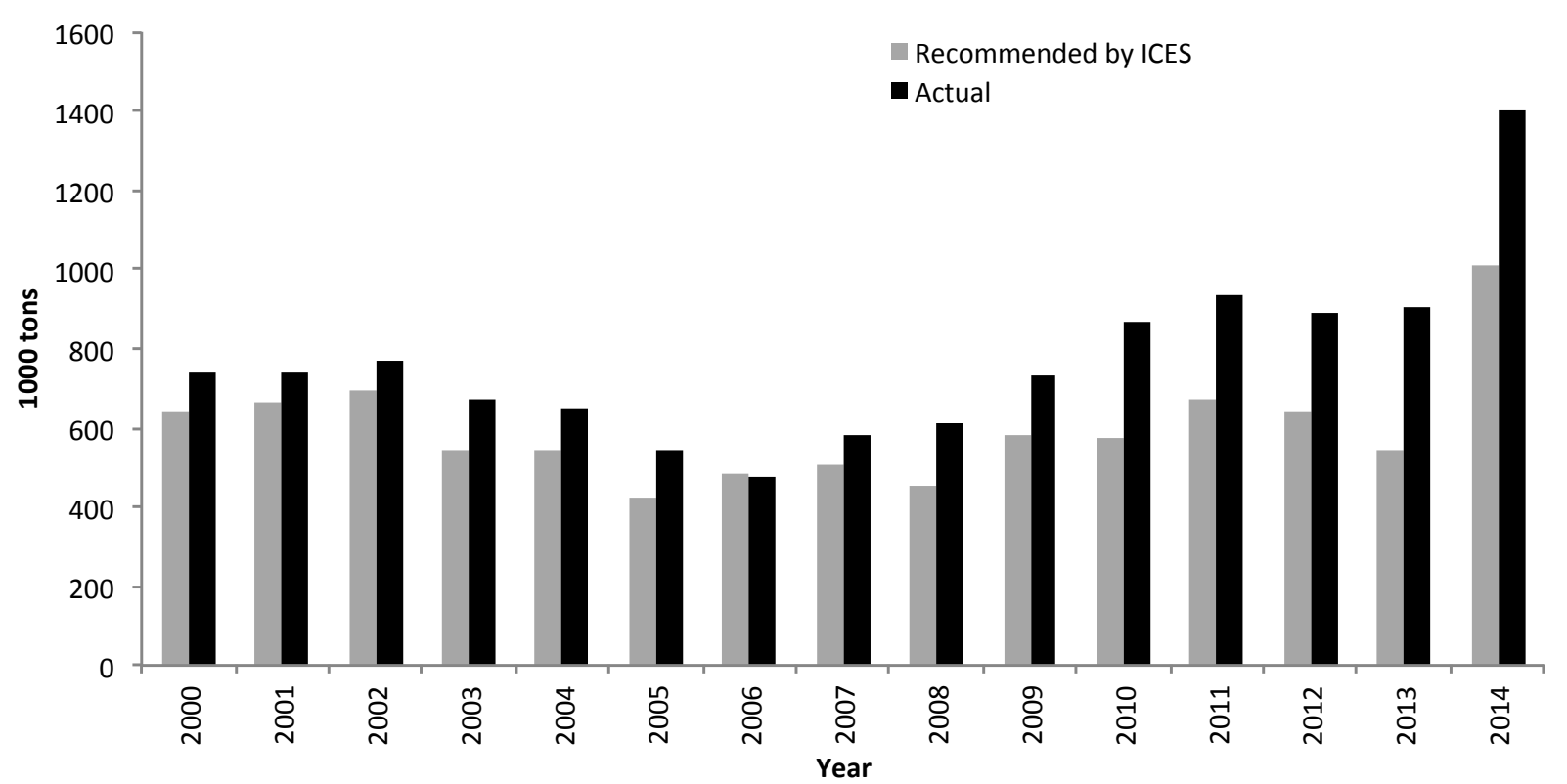

Source: ICES (2014).

Mackerel fishery is seasonal due to an annual migration pattern. The mackerel begins its annual migration by spawning west of Ireland in the spring and then travels north to the Faroe Islands (starting in 2007, it also began traveling to Iceland) in the summer to grow. Next, it travels to the Norwegian coast and northeastern EU waters in the fall, where it is most valuable and easily accessible. Finally, the mackerel returns to the waters west of Ireland in late winter. This is known as the "migration triangle" 4,5 (Figure 2). The stock biomass and the migration patterns in different periods are illustrated in Figure 2.

\footnotetext{
${ }^{3}$ The TAC was raised by $87 \%$ from 542,000 tons in 2013 to 1,011,000 tons in 2014 (Figure 1).

${ }^{4}$ In addition to this migration triangle, some of the mackerel travels south to French, Spanish, and Portuguese seas.

${ }^{5}$ Source: Personal communication during the Pelagic complex conference 2010: Hjalti í Jákupsstovu, former director of the Faroese Marine Institute.
} 
Figure 2: The stock biomass and the distribution area of the NEA mackerel.
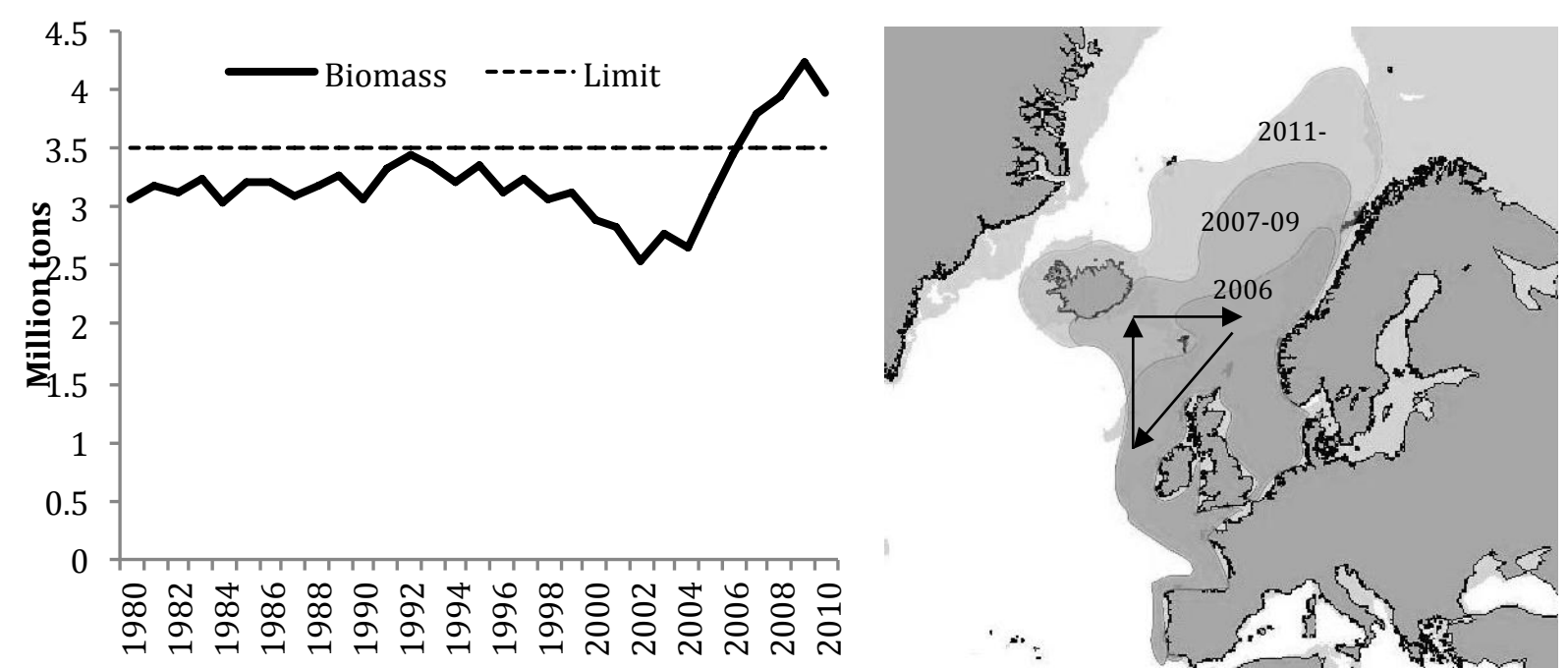

Note: The migration pattern is indicated by arrows.

Sources: ICES (2012); Ellefsen (2013).

While the agreement broke down in 2010 due to changes in migration patterns (an increase in the triangle in Figure 2), it is still uncertain whether this change in migration is temporary, for instance stock dependent, or permanent, for instance due to exogenous more permanent changes. If the stock availability in Icelandic waters is only due to high abundance of the mackerel (above 3.5 million tons, marked with the dashed line in Figure 2), the change in migratory pattern is considered to be of temporary character. If the change in migration pattern is due to longer lasting exogenous changes, such as for example climate change, the change is considered to be of more permanent character. This implies that there are different interpretations of the migration pattern, and parties may have different views on the future state of the stock, which highly affects their threat points in the negotiations. These two-sided explanations are also reflected in ICES (2012), which predicts that the recent change in the migration pattern is most likely due to the larger biomass stock coupled with other reasons, such as changes in the physical environment and the zooplankton concentration and distribution.

\section{Model and Methods}

The population dynamics for the mackerel are described using a discrete-time age-structured model. The number of fish is given by

$$
\begin{gathered}
N_{0, t}=R_{t} \\
N_{i+1, t+1}=N_{i, t} e^{-\left(M+s_{i} F_{t}\right)},
\end{gathered}
$$

where $i=\{0,1,2, \ldots 12\}$ are the classes of mackerel, $R_{t}$ is the recruitment in year $t, F_{t}$ is the fishing 
mortality rate in year $t, s_{i}$ is the selectivity parameter with respect to age class, and $M_{i}$ is the natural mortality rate. The initial $N_{i, 0}$ estimates are based on data from ICES (2010) and given in Table 1. According to the ICES report (2008), the hockey stick recruitment function is used, and is given by:

$$
R_{t}=R_{\max } \min \left(1, \frac{S S B_{t}}{S S B_{\text {break }}}\right)
$$

where $S S B_{t}$ is the spawning stock biomass and $S S B_{\text {break }}$ is the kink on the elbow of the hockey stick function. The spawning stock biomass is given by:

$$
S B B_{t}=\sum_{i=0}^{12} m_{i} w_{i} N_{i, t}
$$

and $m_{i}$ is the mature part (maturity ovary) of the year class $i$, and $w_{i}$ is the stock weight of year class $i$.

Following the Baranov equation the yield (harvest) is given by:

$$
Y_{t}=\sum_{i=0}^{12} \frac{s_{i} F_{t}}{M_{i}+s_{i} F_{t}} W_{i} N_{i, t}\left(1-e^{-\left(M_{i}+s_{i} F_{t}\right)}\right),
$$

where $W_{i}$ is the weight in the harvest, $M_{i}$ is the natural mortality rate and $s_{i}$ is the selectivity in the fishery. Initial sizes for above parameters are given by ICES (2010) for the year 2010 in Table 1.

Phone: +456550 4182 
Table 1: Initial biological data wrt. age class $i$

\begin{tabular}{lllllll}
\hline$i$ & $W_{i}$ & $w_{i}$ & $N_{i, 0}$ & $m_{i}$ & $s_{i}$ & $M_{i}$ \\
\hline 0 & 0.048 & 0 & 3.899 & 0.00 & 0.02 & 0.15 \\
1 & 0.148 & 0.071 & 3.464 & 0.07 & 0.07 & 0.15 \\
2 & 0.222 & 0.150 & 3.188 & 0.58 & 0.20 & 0.15 \\
3 & 0.293 & 0.211 & 2.639 & 0.87 & 0.47 & 0.15 \\
4 & 0.331 & 0.254 & 3.545 & 0.98 & 0.77 & 0.15 \\
5 & 0.365 & 0.299 & 2.543 & 0.99 & 1 & 0.15 \\
6 & 0.418 & 0.351 & 1.074 & 1 & 1.25 & 0.15 \\
7 & 0.470 & 0.393 & 0.521 & 1 & 1.31 & 0.15 \\
8 & 0.487 & 0.414 & 0.655 & 1 & 1.35 & 0.15 \\
9 & 0.515 & 0.445 & 0.237 & 1 & 1.43 & 0.15 \\
10 & 0.573 & 0.484 & 0.059 & 1 & 1.66 & 0.15 \\
11 & 0.604 & 0.552 & 0.432 & 1 & 1.50 & 0.15 \\
12 & 0.629 & 0.571 & 0.032 & 1 & 1.50 & 0.15
\end{tabular}

Note: Weight in the stock $w_{i}$ and weight in the harvest $W_{i}$, are measured in kg. Initial stock $N_{i, 0}$ is individuals in billions. Maturity part $m_{i}$, selectivity $s_{i}$ is without units, and the natural mortality rate $M_{i}$ has the unit per year.

Source: ICES (2010).

\section{Game Setting}

The fishery of the mackerel stock is considered to be performed by two groups of nations, referred to as parties or players: The larger party consisting of EU countries, Norway, and the Faroe Islands, and the smaller party consisting of Iceland. Due to the development in the migration pattern of the stock, as illustrated in Figure 2, the larger party has been involved in the fishery for decades, while the smaller party has only had access to the stock in recent years. Therefore, the larger party is referred to as the incumbent and the smaller party as the entrant. Mason and Polasky (1994) addressed the entry deterrence issue in a renewable resource management setting. In their setting, there is a sole exploiter of the resource, who is worried about the potential entry of a new exploiter. The incumbent fisherman promotes an active entry deterrence strategy by increasing present harvest levels; this strategy would reduce the likelihood of future entry, which would, in turn, reduce future rents for the incumbent. The setting in our paper is quite similar, but instead of being able to deter entrants on the basis of price levels, the deterrence is based on the stock dynamics, and an agreement therefore depends on the perception of the ecosystem.

To reflect the uncertainties in the availability of the North-East Atlantic mackerel, two possible 
scenarios are conjectured in this paper. The two scenarios are referred to as a temporary or a permanent change. The two scenarios are defined based on the availability to parties involved in the fishery:

Temporary Change. In this scenario, the migration pattern is assumed purely stock dependent, and, since changes in stock size will change the migration pattern, the migration pattern is of a temporary character. It is assumed that the stock is continuously in incumbent waters while only enters entrant waters temporarily when the stock is above a certain limit. In the case of the NorthEast Atlantic mackerel this happens when the stock is above 3.5 million tons as illustrated by the dashed line in Figure 2. ${ }^{6}$

Permanent Change: In this scenario, the change in migration pattern is assumed to be of a permanent character, not connected with the stock size but caused by exogenous permanent factors, like for example climate change. The permanent character implies that the stock, independently of stock size, is continuously available in both the incumbent's and the entrant's waters.

The benefit, i.e. the resource rent, from the fishery to the player $j \in\{$ entrant, incumbent $\}$ at time $t$, is defined as:

$$
\pi_{j, t}=p Y_{j, t}-c_{j} F_{j, t}
$$

where $p$ is the landed value, measured in unit price per weight, of the mackerel, and $c_{j}$ represents the unit costs of applying one unit of fishing mortality. The unit price is based on Nielsen et al. (2010), and the cost parameter is calibrated such that the total costs of fishing in 2010 were approximately $50 \%$ of the revenue in 2010 , when the model is solved. The cost function suggests the costs is proportional with fishing mortality. In the appendix there is a discussion of the cost function together with the below analysis run under the assumption of costs being proportional to harvest.

We run a simulation model in Matlab by MathWorks ${ }^{\circledR}$ for a time period of $T=50$ years, which is a sufficiently long time horizon to ensure equilibrium and to be a proxy for an infinite time horizon, under the two different scenarios of the migration of mackerel stock. Based on a simultaneous move game and subject to the joint resource constraint, each group of nations is expected to maximize the present value of the fishery:

$$
\max _{F} \sum_{t=0}^{T} \pi_{t}(1+\delta)^{-t}
$$

\footnotetext{
${ }^{6}$ In the 1970s the stock size exceeded this limit, but this is assumed to have been due to another North Sea stock of the mackerel, which no longer exists. This conjecture is the same as in Hannesson (2012). 
where $\delta$ is the social discount rate. ${ }^{7}$

In the game theoretical literature applied to fisheries, there is a tendency to assume that the players admit to only adhere to one strategy for the whole simulation period (Sumaila, 1999). In this paper, this assumption is relaxed by allowing players to change strategy during the game. More specifically, the incumbent player can have different fishing mortalities depending on whether the entrant is in the game or not. Likewise, the entrant can have different fishing mortalities, but without loss of generality it is assumed that the fishing mortality for the entrant is zero if the stock is not available within its regional zone and positive if the stock is in the regional zone (i.e., the stock size is exceeding the temporary limit, which for mackerel is 3.5 million tons). Table 2 illustrates the game setting defined by different strategies to the different ecological states in the two scenarios.

Table 2: Fishing mortalities $(F)$ for different ecological states

\begin{tabular}{llcl}
\hline & \multicolumn{2}{c}{ Temporary change } & Permanent change \\
\cline { 1 - 2 } & stock $>3.5 \mathrm{~m}$ tons & stock $<3.5 \mathrm{~m}$ tons & \\
\hline Entrant & $F_{\text {entrant }(\text { temp })}$ & 0 & $F_{\text {entrant }(\text { perm })}$ \\
Incumbent & $F_{\text {incumbent }(\text { temp })}^{\text {high }}$ & $F_{\text {incumbent }(\text { temp })}^{\text {low }}$ & $F_{\text {incumbent }(\text { perm })}$ \\
& & & \\
\hline
\end{tabular}

We assume that the entrant cannot have a fishing mortality rate above 0.05 per year because of lack of access to a larger share of the stock. Thus, in this simulation model there are two players when the stock is above 3.5 million tons and only one player when the stock is below 3.5 million tons. Given these conditions, the optimal fishing mortality for both players for all periods is determined in a competitive Nash equilibrium, where each player adopts its mutually best response, and in a cooperative solution, where the global rents from the fishery is maximized. The applied parameter values for maximization are summarized in Table 3.

\footnotetext{
${ }^{7}$ It is, without loss of generality, assumed that the players face the same social discount rate. One could argue that the incumbent is likely to be more farsighted than the entrant $\left(\delta_{\text {incumbent }}<\delta_{\text {entrant }}\right)$, but this would not change the overall conclusion of the paper.
} 
Table 3: Parameters for the model

\begin{tabular}{cll}
\hline Parameter & Value & Unit \\
\hline$R_{\max }$ & 2.66 & Billion individuals \\
$S S B_{\text {break }}$ & 4.07 & Billion individuals \\
$p$ & 8.00 & NOK per kg \\
$c_{\text {incumbent }}$ & $14,000,000$ & NOK per unit effort \\
$c_{\text {entrant }}$ & $14,000,000$ & NOK per unit effort \\
$\delta$ & 0.02 & Per year \\
$F(\text { max })_{\text {entrant }}$ & 0.05 & Per year \\
\hline
\end{tabular}

\section{Results}

The model is simulated over a sufficiently long time horizon (50 years) to ensure that a steady state is reached. Figure 3 demonstrates the biomass and harvest for different parties under different ecological scenarios and management regimes (e.g., Nash or cooperative). The biomass and harvest development under cooperative management is the same for both scenarios because the stock dynamic is independent of the scenarios and, under a cooperative management, players act as one unity. Hence it does not mater which player lands the harvest. The consequences for the biomass stock under the different scenarios are: that a cooperative solution leads to higher biomass than under Nash solutions, and the Nash equilibrium in the temporary scenario demonstrates higher biomass than the Nash solution in the permanent scenario. The explanation behind this can be found in the harvest data illustrated in panel B in Figure 3; in the permanent scenario there is a situation where, because the mackerel is always in Icelandic waters, the players have to harvest the fish before each other. It leads to the largest total harvest, shared between the players. However, the corresponding biomass (panel A) is relatively low, around 3.3 million tons, and this leads, despite the large harvest, to a low total economic outcome. The economic outcome is low because of lower production in the population and higher cost of fishing caused by low density of fish. The permanent scenario illustrates the traditional tragedy of the commons, where parties, not considering the total economic outcome but instead maximizing their own individual rent, degrade the resource.

In the temporary scenario the entrant will, after 5 years, have no harvest left as shown in panel $\mathrm{C}$ of Figure 3. The reason behind this can be seen in panel A as the biomass settles around 3.5 million tons, and hence the incumbent controls the migration of the mackerel by fishing such that the stock is just at the threshold for migration. By this, the incumbent can deter the entrant from any harvest, and the incumbent remains in the fishery without competition as long as the stock is kept low. The best response for the incumbent party is, therefore, to fish such that the stock biomass remains exactly below the limit where the stock migrates into Icelandic waters, and the best response for the entrant is to fish as much as possible and as soon as possible, to maximize benefits in the period 
when the stock is available. This leads overall to a higher biomass stock than under the permanent scenario, a slightly lower total harvest, but lower cost of fishing; resulting in a better total outcome than under the permanent scenario.

Under the cooperative management there is no difference in whether the change is of permanent or temporary character. The harvest is lower than under the Nash solution; however, the biomass is higher, which leads to a lower cost of fishing. The cooperative management is, therefore, first-best in economic rents. The difference between the total economic outcome in the cooperative and temporary scenario is not that large, as the incumbent can maximize the outcome if they keep the stock small enough to deter the entrant from fishing.

Figure 3: Population dynamics (million tons) and total harvest (tons) in different scenarios and management regimes

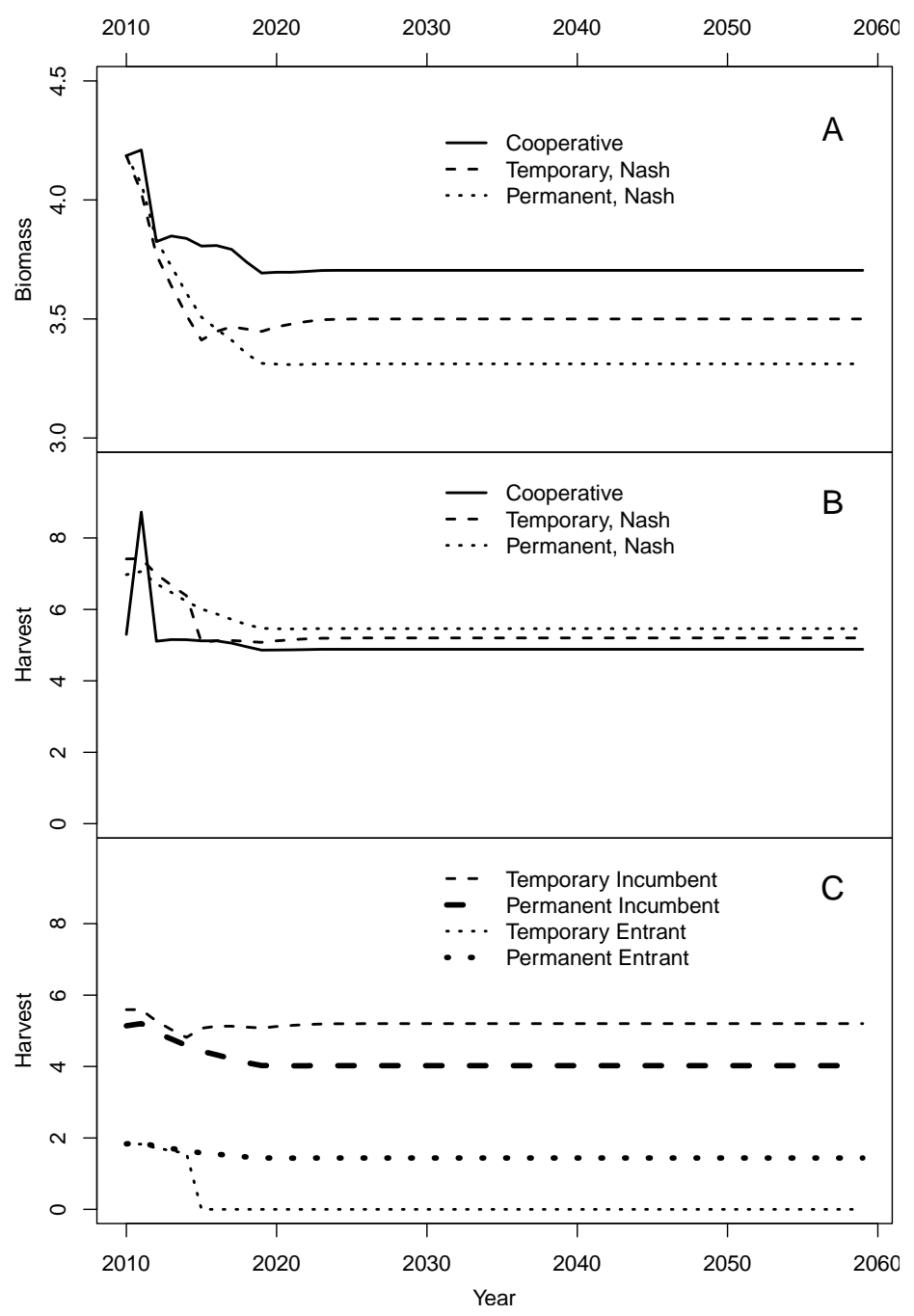

Note: Panel A illustrates population dynamics in different scenarios and management regimes. Panel B illustrates total harvest in different scenarios and management regimes. Panel C illustrates individual parties' harvest in Nash equilibrium under different scenarios. 
The total rents from the fishery under the two scenarios, comparing cooperative management and Nash behavior are summarized in Figure 4, where the left-hand panel assumes the permanent scenario and the right-hand panel assumes the temporary scenario. In each panel the right box shows the outcome for each of the players under a Nash game, and the left box shows the total outcome under cooperative management. The cooperative solution, where global rents are maximized yields first-best outcome. There is no difference in the cooperative solution whether the stock is facing a temporary or a permanent change since the overall objective is unchanged and costs are unchanged with the location of the stock. Also, as expected, the total rents in the noncooperative game under the temporary scenario exceed the rents under the permanent scenario since the strategies adopted demonstrate a more conservative exploitation of the stocks. The allocation of rents between incumbent and entrants differs significantly in the two scenarios. This is due to the fact that under the temporary scenario the incumbent player has an entry deterrence possibility. This means that the entrant is only part of the game when the stock level is high, as has been the case in recent years, and hence is deterred from harvesting in the subsequent years. The more conservative nature of the incumbent's strategy implies higher rents, as also illustrated in Figure 4. Under the permanent scenario, there is a less conservative nature of the strategies and rents occur to both parties throughout the entire time horizon. Hence, the entrant prefers the permanent scenario, while the incumbent prefers the temporary scenario. 
Figure 4: Total rents (billion NOK) in the cooperative solution and Nash equilibrium.

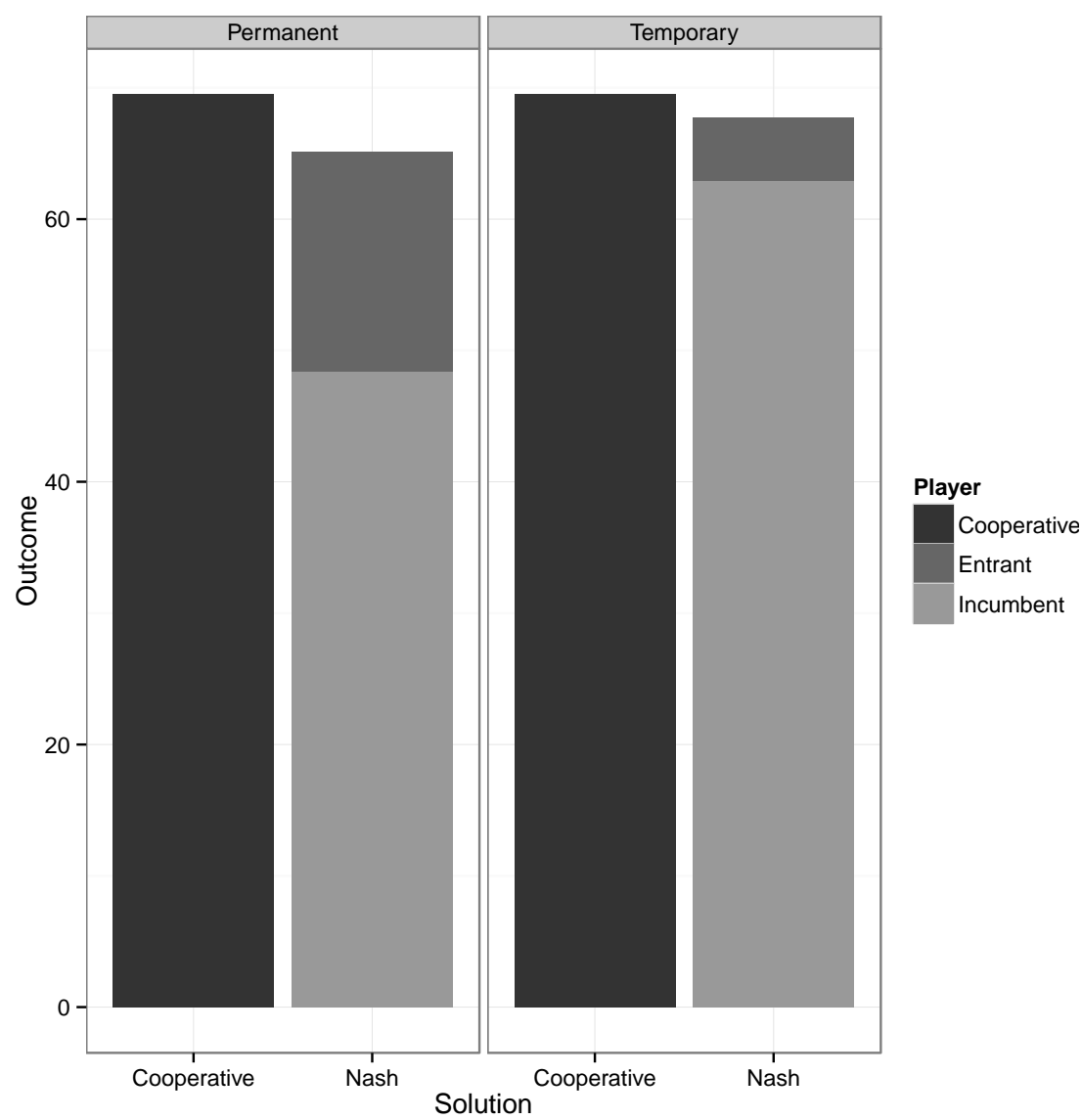

Note: The outcome corresponds to total rents in billion NOK.

In each panel the left-hand box shows cooperative management and the right-hand box show the Nash game.

Figure 5 combines the total rents in the fishery for the cooperative and the Nash equilibrium under the two scenarios. The total height of the black columns illustrates the cooperative rents. The cooperative rents are independent of the ecological state. The dark grey area illustrates the rents to the entrant, and the light grey area illustrates the rents to the incumbent, both under a competitive Nash game, which can be regarded as the parties' positions during negotiation. During a negotiation where the outcome from the cooperation are to be shared by agreement, each player will not accept less than under the Nash solution; the light and dark grey boxes in Figure 5. Hence, the two parties' Nash rents can be regarded as the their individual threat points for joining a cooperative solution. The residual of the cooperative rents, illustrated as the black area, are thus the excess benefits or surplus from cooperation, which can be used for sharing under the negotiation of a joint solution. If the two parties agree about the state of the stock, for example which scenario the stock follows, the two scenarios can be regarded independently, and the conclusion is that there is a likelihood of obtaining a stable, high rent-generating outcome in the fishery. If, however, parties are of different opinions about the ecological state of the stock, for instance which scenario the stock follows, the conclusions are far more pessimistic. Figure 5 demonstrates the difficulties in achieving a 
cooperative solution to the problem if incumbent believes that the change in migration pattern is of a temporary character, while the entrant believes it is of a permanent character. The expected outcome for each player will, with different views on the ecology, sum to more than the cooperative solution. This can be seen by the dark grey box on the left-hand in Figure 5, overlapping the light grey box on the right-hand. There is then no way a negotiation can ensure that players are better off than under the Nash game. With different views about the ecology of a fish stock a cooperative solution can thus be very difficult to achieve.

Figure 5: Total rents of simulations (billion NOK)

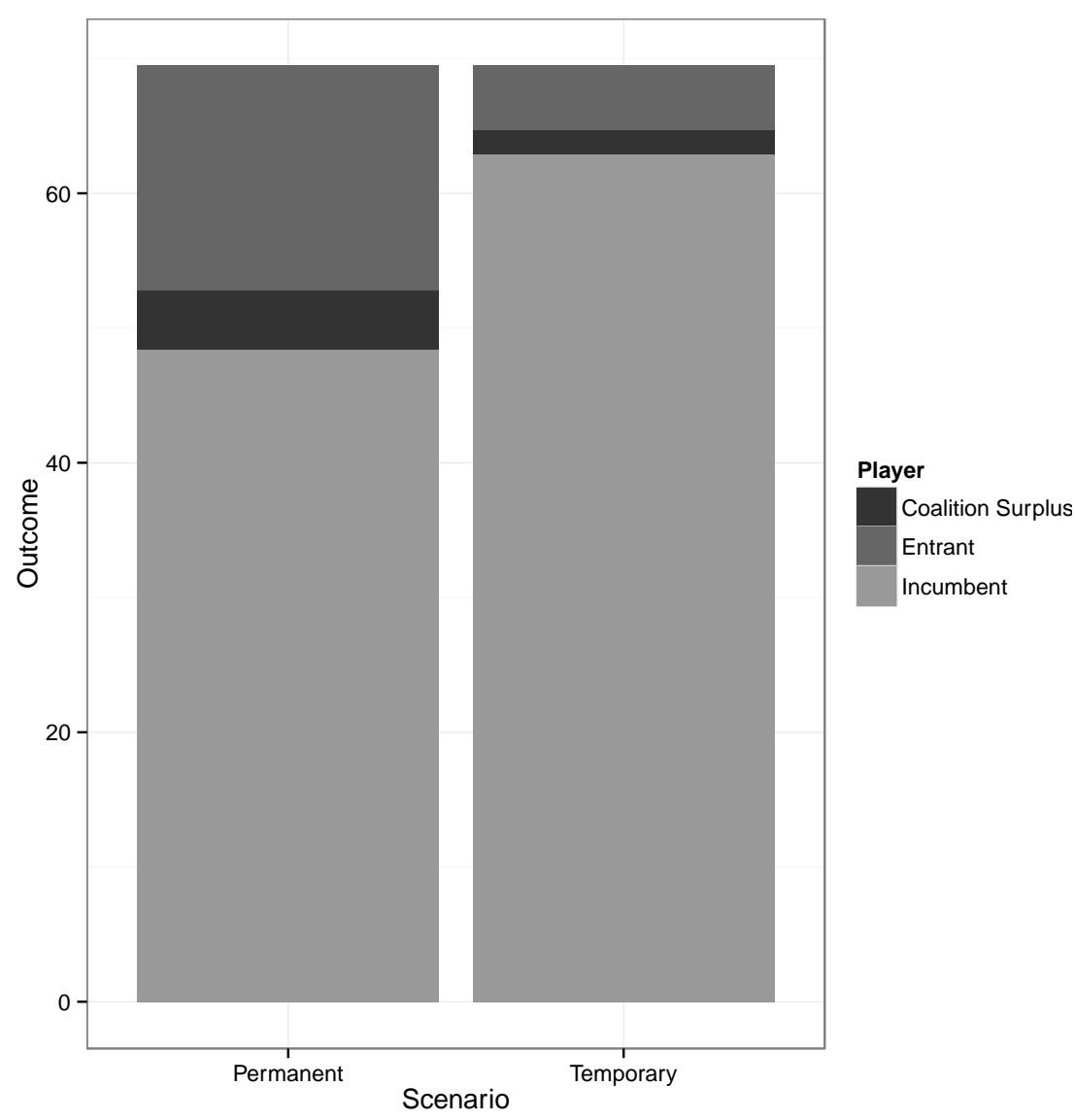

Note: The outcome corresponds to total rents in billion NOK. In each panel the height of the box is the cooperative rents. The dark and light grey boxes are the outcome for each party playing a Nash game; the black is the excess benefit of cooperation to be shared between parties during negotiation.

The parameters of the cost function have been estimated or assumed to lie within a range of values (see the appendix for a discussion). Especially the values for the parameter describing the degree of schooling are seen in the whole range from equal density distribution to full schooling fishery. The above analysis assumes equal density distribution. To test if this assumption affects the results, the same analysis has been performed in the appendix with, full schooling. The change in parameter do not change the outcome of the game: The expected outcome for each player will, with different 
views on the ecology, sum to more than the cooperative solution (Figure A2) and the conclusion remains unchanged; namely a negotiation cannot ensure players are better off than under the Nash game.

\section{Stochastic Recruitment}

The presented model applies the deterministic Hockey-stick recruitment (equation (3)) for the mackerel stock. Due to the uncertainties on the type of stock-recruitment relationship, and to the existence of a stock-recruitment relation at all, (Hannesson, 2012) estimations are re-run using a stochastic recruitment function with a simulation that runs 200 times. The stochasticity allows for an analysis of likely probabilities for future development. A normal distribution is used for the recruitment, and it is assumed that the average recruitment is the same as it has been for the past 40 years. Furthermore, the standard deviation is also the same as the historical deviation. The rents of the fishery for both the entrant and the incumbent are compared to the previous model for a period of 50 years. Only the temporary change scenario is considered in the case of the stochastic recruitment.

The entrant only has incentives to start fishing when the mackerel is available in their EEZ, and the incumbent has incentives to - if possible - deter the entrant from fishing. Whenever the stock size is below 3.5 million tons, the fishing mortality of the incumbent is the rent maximizing fishing mortality rate of 0.1648 per year. When the stock size is above 3.5 million tons, the entrant applies the maximum fishing mortality rate of 0.05 per year, while the incumbent has a variable fishing mortality rate in the range of 0.09 to 0.30 per year. Based on this, the rent maximizing fishing mortality for the incumbent results in an equilibrium biomass just below 3.5 million tons. Thereby, it is likely that, with stochastic recruitment, ensruing the rent maximizing fishing mortality means that the stock exceeds the threshold and enters the entrant's waters from time to time.

Figure 6 summarizes the results for rents when the incumbent has fishing mortality rates in the range of 0.09 to 0.30 per year in the case where the stock is higher than 3.5 million tons, and otherwise 0.1648 per year. The dotted line shows the likelihood of the stock entering Icelandic waters by each of the strategies.

\footnotetext{
* Corresponding author. 
Figure 6: Relationship between rents, fishing mortality rates, and likelihood of exceeding the threshold for the stock entering Icelandic waters

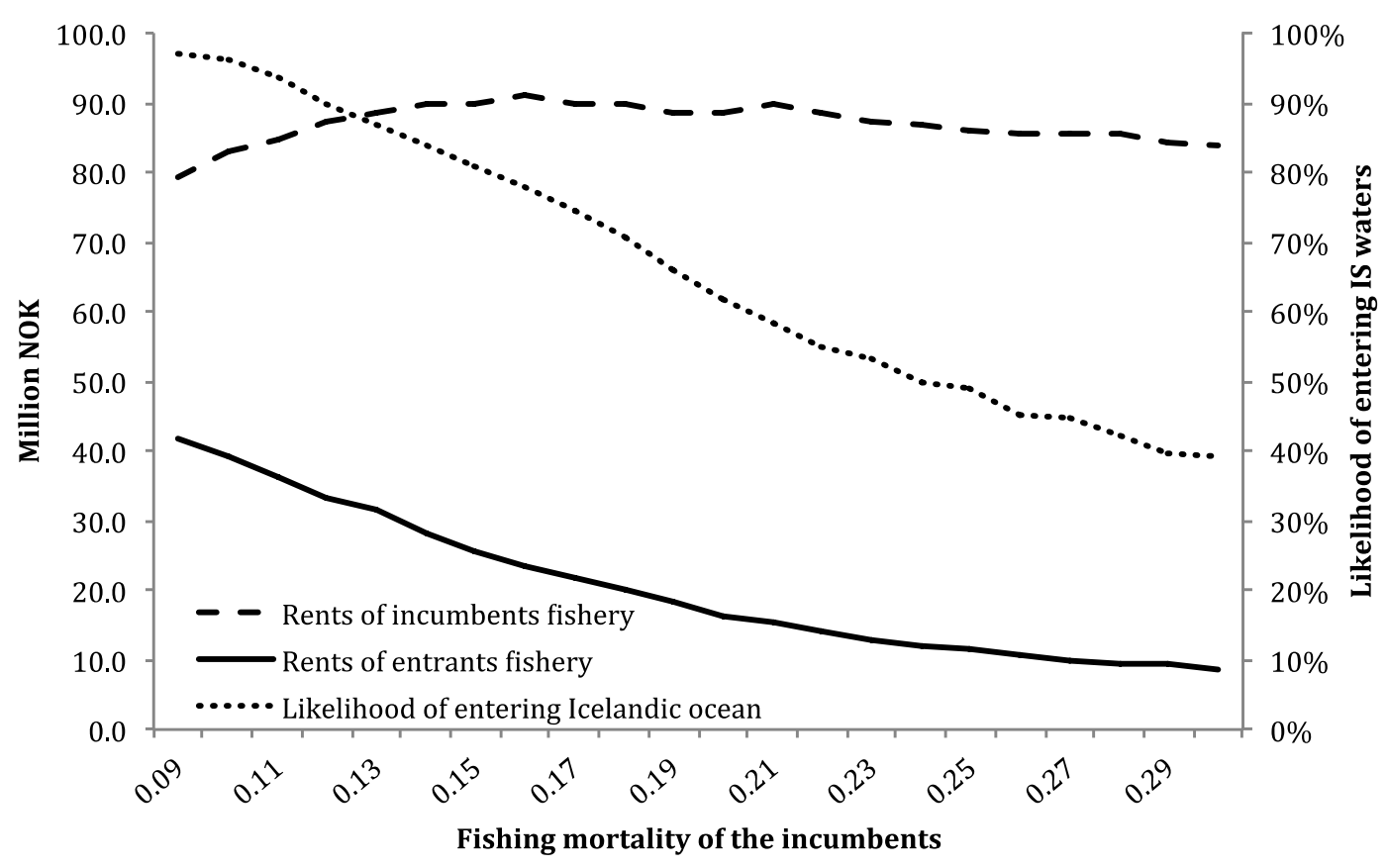

As illustrated in Figure 6, fluctuations in the incumbent's rent to the different fishing mortalities are small, while the incumbent's fishing mortality significantly affects for the entrant's rent. The sum of the total rents is highest when the fishing mortality rate is fairly low, 0.10 per year for the incumbent and 0.05 per year for the entrant. In an agreement, a transferable utility game would then imply that the entrant would pay the incumbent to sign the agreement and get at least the maximum rents.

When there is no agreement between the incumbent and the entrant (as was the case in April 2014), the most profitable strategy for the incumbent is to employ a fishing mortality rate of 0.16 per year in addition to the entrant's fishing mortality rate of 0.05 per year when the stock is high. This implies that the likelihood of the mackerel entering Icelandic waters is around $80 \%$ leading to a lower rent for the entrant. If the fishing mortality rate of the incumbent is raised to 0.3 per year, the likelihood of the stock entering Icelandic waters drops to below $40 \%$, while the rent is reduced significantly for the entrant, with a much less significant drop in rents for the incumbent.

The model builds upon the assumption of a fishing mortality rate of 0.05 per year for the entrant. With a higher fishing mortality, e.g. in 2014, Greenland is also an entrant. This lowers the stock and decreases the likelihood of the stock entering Icelandic/Greenlandic waters, still assuming that this is a temporary migration change. Also, the model with stochastic recruitment builds upon a static fishing mortality rate assumption for the incumbent when the stock is below 3.5 million tons. 
Another strategy to be considered is that the incumbent raises the fishing mortality rate when the stock is below 3.5 million tons. This would imply lower rents for incumbents, but on the other hand also lower likelihood for the stock to enter Icelandic waters.

\section{Discussion}

The paper demonstrates how diverging views on the ecosystem can lead to the breaking down of management agreements. This is also true in cases where there is a possibility for economic improvement for both parties with an agreement, compared to the Nash equilibrium when scenarios are regarded in isolation. The problem is that when the different views are combined, the possibility of entering agreements with economic improvements to both parties can vanish.

The results are demonstrated through empirical application to the North-East Atlantic mackerel, where disagreements about the migration pattern are likely to cause a collapse of negotiations among some of the fishing parties. The disagreement involves different views about a temporary and a permanent change in the migration pattern. Our analysis shows that disagreements regarding the ecology of the fish population can render negotiations for international fisheries agreements impossible. The result of failing to reach an agreement is that the nations will apply a higher fishing pressure than under an agreement. This results in some periods of extremely high fishing pressure because a demonstration of the potential of high fishing pressure is an argument in the negotiations. The higher fishing pressure due to the lacking agreements leads both to stress on the fish stock and a lower combined economic outcome. Hence, the breakdown of agreements implies a pressure on both the fish stock and the economic welfare.

In the temporary scenario the incumbent is deterring the entrant from fishing by fishing so that the mackerel does not enter the entrant's waters. Hence, instead of traditional entry deterrence based on rents, the entry deterrence is based on the stock dynamics. From the industrial organization literature, it is known that entry deterrence reduces welfare because the incumbent can continue its monopolistic behavior if the entry deterrence is successful. For renewable resources, this situation is quite different because the welfare-maximizing level of output is not the fully competitive situation (which is equivalent to an open-access situation). Additionally, the sole owner cannot influence the price and is therefore not a monopolist in a traditional sense. If entry deterrence suppresses the total harvest below the open access level, then the effect on the total welfare is ambiguous. On the one hand, lower harvest imply higher resource rents. On the other hand, the restricted competition means that the industry is less dynamically efficient.

The presented model builds upon a static view of nature, which could be referred to as an either/or presentation of scenarios, involving only a single species. We acknowledge the uncertainty in the 
recruitment function by exploring the consequences of stochastic recruitment. The results from stochastic recruitment demonstrate robustness since the incumbent still has incentives to overfish in order deter the entrant. Because of the stochasticity the strategy of just keeping the stock below the threshold is no longer sufficient. If the incumbent chooses to have a much higher fishing mortality rate when the stock is above the threshold, then this has only little effect on the incumbent's rent, whereas it has a large impact on the entrant's rent.

The path-breaking part of the model includes the step from open membership to a semi-open membership game with possibility of revision of harvest strategies depending on the presence of both players, or not both players, in the game. The model allows for illustrating the conflicts that can arise with different views of the ecological framework conditions, but could be expanded to include issue linkage, with for example other species or trades, which could be coupled to the agreement to increase the likelihood of achieving a Pareto improvement.

The model is limited to fixed economic parameters over the estimated time horizon. It may be argued that this is not a reasonable assumption, but it is outside the scope of this paper to analyze the consequences of technological progress or economic development of price levels.

We demonstrate that uncertainty regarding the migration pattern of the fish can lead to the breakdown of an international fishery agreement. The spontaneous reaction to this conclusion could be to advocate for more research into the ecology of the fish population. However, we do not see this as a solution. The standard fishery agreements, like the one for the North-East Atlantic mackerel, will normally be based on a fixed sharing rule of, for instance, a total allowable catch set by the ICES. Implicitly, this assumes that the ecology of the fish population is static. Contrary to this we see the ecosystem be populated by a dynamic community of fish populations. The dynamic of this community with respect to both population dynamic and migration pattern is unpredictable on the medium and the long-term term. It seems inappropriate to base international agreements on a property that is highly variable since this involves the implicit assumption that it is fixed. Alternatively, our suggestion must be to form the agreements on other properties that are more stable. Therefore, we advocate research that attempts to pinpoint the properties of the marine ecosystems that are stable enough to form the basis for sharing rules for long-lasting international agreements.

\footnotetext{
* Corresponding author.

E-mail address: lg@sam.sdu.dk (L.G. Kronbak) 


\section{Literature}

Arnason, R., G. Magnusson, and S. Agnarsson. 2000. The Norwegian Spring-Spawning Herring Fishery: A Stylized Game Model. Marine Resource Economics 15(4): 293-319.

Bjørndal, T and D.V. Gordon. 2000. The Economic Structure of Harvesting for Three Vessel Types in the Norwegian Spring-Spawning Herring Fishery. Marine Resource Economics 15(4): 281-292.

Bjørndal, T., D.V. Gordon, V. Kaitala, and Lindroos, M. 2004. International Management Stragegies for the Norwegian Spring Spawning Fishery: A Bio-Economic Simulation Model of the Norwegian SpringSpawning Herring Fishery. Environmental and Resource Economics 29(4): 435-457.

Bjørndal, T., and G.R. Munro. 2003. The Management of High Seas Fisheries. In H. Folmer and T. Tietenberg (eds.). The International Yearbook of Environmental and Resource Economics 2003/2004. Cheltenham, UK: Elgar: 1-35.

Ellefsen, H. 2013. The stability of fisheries agreement with entry: The case of the NEA mackerel. Strategic Behavior and the Environment, 3(1-2): 67-95.

Hannesson, R. 2012. Sharing the Northeast Atlantic Mackerel. ICES Journal of Marine Science (doi:10.1093/icesjms/fss134).

ICES 2007. Report of the Working Group on NEA Mackerel Long-Term Management Scientific Evaluations (NEAMACKLTM).

ICES. 2008. Report of the ICES Advisory Committee, 2008. ICES Advice, 2008. Book 9.

ICES. 2010 Report of the ICES Advisory Committee, 2010. ICES Advice, 2010. Book 9.

ICES. 2012. Report of the ICES Advisory Committee, 2012. ICES Advice, 2012. Book 9.

ICES. 2013. Report of the ICES Advisory Committee, 2013. ICES Advice, 2013. Book 9.

ICES. 2014. Report of the ICES Advisory Committee, 2014. ICES Advice, 2014. Book 9.

Kaitala, V., and G. Munro. 1997. The Conservation and Management of High Seas Fishery Resources Under the New Law of the Sea. Natural Resource Modeling 10:87-108.

Kennedy, J. 2003. Scope for efficient multinational exploitation of North-East Atlantic Mackerel. Marine Resource Economics 8(1): 55-80.

Kronbak, L., and M. Lindroos. 2007. Sharing Rules and Stability in Coalition Games with Externalities. Marine Resource Economics 22(2): 137-154.

Kronbak, L., and M. Lindroos. 2013. Allocation and sharing in international fisheries agreements. Food economics 9(3): 186-198.

Lindroos, M., Kronbak L., Kaitala V. 2007. Coalitions in fisheries games. In: Bjørndal T., Gordon D., Arnason R., Sumaila U. (eds) Advances in fisheries economics - festschrift in honour of Professor Gordon R. Munro. Blackwell: 184-195.

Mason, C.F., and S. Polasky. 1994. Entry Deterrence in the Commons. International Economic Review 35: 507-525.

Munro, G.R. 2007. Internationally shared fish stocks, the high seas, and property rights in fisheries. Marine Resource Economics 22: 425-443.

\footnotetext{
* Corresponding author.

E-mail address: lg@sam.sdu.dk (L.G. Kronbak)

Phone: +45 65504182
} 
Munro, G.R. 2008. Game theory and the development of resource management policy: The case of international fisheries, in Game Theory and Policymaking in Natural Resources and the Environment, A. Dinar, J. Albiac, and J. Sánchez-Soriano (eds.), Routledge Explorations in Environmental Economics, chap. 2: 12-41. Routledge, London, UK; New York, USA.

Nielsen, M., P. Andersen, L. Ravensbeck, F.M. Laugesen, J. Andersen, D.M. Kristoffersen, S. Reithe, J. Nilssen, and H. Ellefsen. 2010. Socio-Economic Return of Pelagic Fisheries in the Northeast Atlantic Ocean (in Danish). Nordic council. Theme North 2010:573.

Pintassilgo, P., and C.C. Duarte. 2000. The New-Member Problem in the Cooperative Management of High. Marine Resource Economics 15(4): 361-378.

Rahikainen, M., M. Lindroos, and V. Kaitala. 2013. Stability of international fisheries agreements using precautionary bioeconomic harvesting strategies. Strategic Behavior and the Environment 3: 97-120.

Sumaila, U.R. 1999. A review of game-theoretic models of fishing. Marine Policy, 23(1): 1-10.

United Nations. 1982. United Nations Convention on the Law of the Sea. UN Doc. A/Conf.62/122.

United Nations. 1995. United Nations Conference on Straddling Fish Stocks and Highly Migratory Fish Stocks. Agreement for the implementation of the United Nations Convention on the Law of the Sea of 10 December 1982 relating to the conservation and management of straddling fish stocks and highly migratory fish stocks, UN Doc. A/Conf./164/37.

Warming, J. 1911. Om Grundrente af Fiskegrunde (In English: On Rent of Fishing Grounds). Nationaløkonomisk Tidsskrift 49: 499-505. 


\section{Appendix - Costs of fishing}

Cost functions are not easily determined, and there are no empirical data available for this specific fishery. As an alternative approach, we examine different cost functions that have been used in the literature for this type of schooling fisheries in the North-East Atlantic. In studying the mackerel, Kennedy (2003) introduces a cost function for the mackerel based on the production function

$$
H=E^{a} X^{b},
$$

where $E$ is effort, $X$ is the stock, and $a$ and $b$ are parameters. Costs are assumed to consist of constant unit costs of effort, called $c$, giving a total cost of

$$
T C=c H^{1 / a} X^{-b / a} .
$$

In Kennedy (2003), the parameter $a$ is assumed to be either 0.6 or 0.8. $a<1$ indicates a production function (A.1) with decreasing returns to scale. This is to be expected if the fleet is already fully employed and the effort has to be increased without allowing new vessels into the fishery. However, if the fishing capital market is flexible and there is underutilized capital available, adding or deducting vessels from this fishery should only scale the production function. We assume a flexible market with available fishing capital and therefore assume $a=1$.

The parameter $b$ reflects the degree of schooling. One extreme is full schooling such that $b=0$; the other extreme is an equal density distribution of the stock such that $b=1$. The Kennedy (2003) article uses $b$ values of $0,0.6$, or 1 . Other empirical approaches for estimating a cost function for a schooling fishery in the NEA relate to the Norwegian Spring Spawning (NSS) herring fishery. Bjørndal and Gordon (2000) have estimated a cost function for the NSS herring fishery, which is also applied in Bjørndal et al. (2004). This type of cost function is dependent only on the harvest and not on the stock; thus, it assumes a full schooling fishery, corresponding to $b=0$ in equations (A.1) and (A.2). Arnason et al. (2000) also examine the NSS herring fishery, and they assume a full schooling fishery; however, they also introduce a parameter to account for the distance to the fishing fields when determining the costs. The present paper does not consider the distance component, as the cost of traveling a distance is not a significant part of the cost of fishing in the NEA mackerel fishery (source: personal communication with Tórheðin Jensen, June 2009). Finally, some studies examine the NSS herring fishery and specify costs as a function of only $F$ (fishing mortality rate), corresponding to $b=1$ in equations (A.1) and (A.2) (e.g., Rahikainen et al., 2013). This brief overview of applied cost functions in schooling fisheries in the NEA makes it clear that there is a wide variety of cost functions that can be used to describe a pelagic schooling fishery.

\footnotetext{
* Corresponding author. 
In the main article we have used the case where $b=1$. To analyze if this specific choice of parameter affects the conclusion of the article, the model is here run with the parameter set at the other extreme to $b=0$. In both cases the cost function is calibrated by setting the variable $c$ such that the total costs of fishing in 2010 were approximately $50 \%$ of the revenue. This calibration is in line with what has been found to be the resource rent in the NEA pelagic fishery (Nielsen et al., 2010).

The results of the sensitivity analyzes is presented in Figures A1 and A2 which correspond to Figures 4 and 5 in the article.

Figure A1: Total rents (billion NOK) in cooperative solution and Nash equilibrium

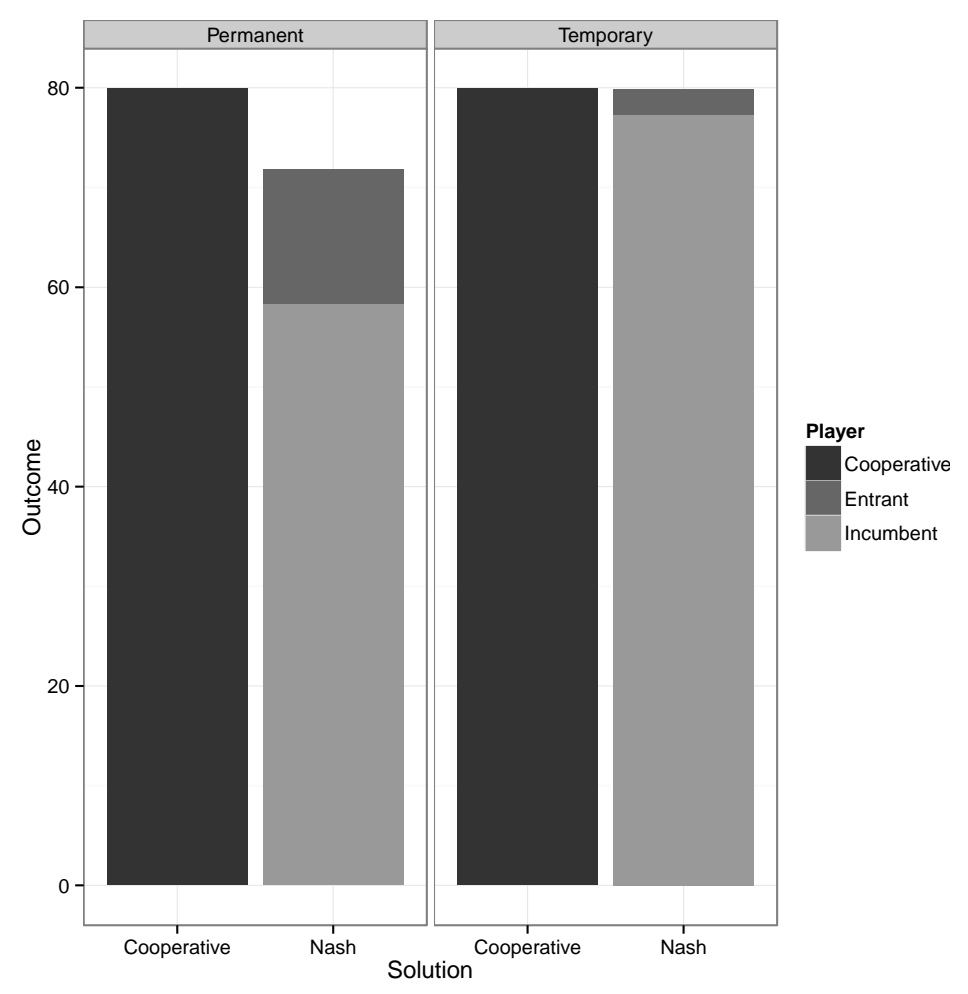

Note: The outcome corresponds to total rents in billion NOK.

In each panel the left box shows cooperative management and right box show the Nash game. 
Figure A2: Total rents of simulations (billion NOK)

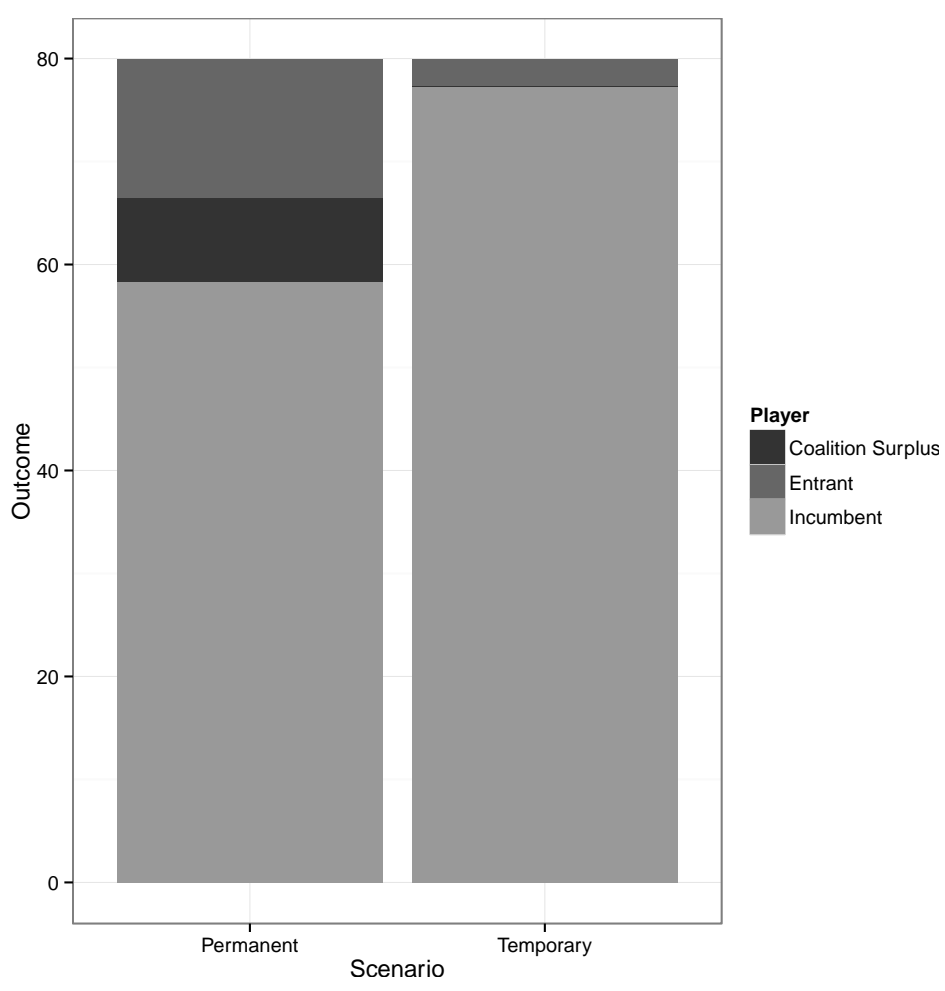

Note: The outcome corresponds to total rents in billion NOK.

In each panel the height of the box shows cooperative rents. The dark and light grey boxes are the outcome for each party playing a Nash game; the black box is the excess benefit of cooperation to be shared between parties under negotiation. 